\title{
Impact of COVID 19 on Indian Migrant Workers: Decoding Twitter Data by Text Mining
}

\author{
Pooja Misra $^{1}$ D . Jaya Gupta ${ }^{1}$
}

Accepted: 23 May 2021 / Published online: 20 July 2021

(c) Indian Society of Labour Economics 2021

\begin{abstract}
The Coronavirus pandemic has induced a huge economic crisis. The norms of social distancing and consequent lockdown to flatten the curve of this infection has brought economic activity across the globe to a standstill. A mass exodus of workers from major urban centres of India to their native villages started. Mental, financial and emotional agony inflicted due to job-loss, lack of job and livelihood opportunities led to this. A massive macroeconomic crisis for the country with serious ramifications has consequently exploded. The present study explores and captures the diffusion and discovery of information about the various facets of reverse migration in India using Twitter mining. Tweets provide extensive opportunities to extract social perceptions and insights relevant to migration of workers. The massive Twitter data were analysed by applying text mining technique and sentiment analysis. The results of the analysis highlight five major themes. The sentiment analysis confirms the confidence and trust in the minds of masses about tiding through this crisis with government support. The study brings out the major macroeconomic ramifications of this reverse migration. The study's findings indicate that a concentrated joint intervention by the State and Central Governments is critical for successfully tiding through this crisis and restoring normalcy. The subsequent policy measures announced by the government are being critically gauged. In addition, the authors have proposed measures to ameliorate this damage on the formal and informal sectors.
\end{abstract}

Keywords Covid19 · Migrant workers · Indian economy · Lockdown · Plight · Policy measures

JEL Classification E0 $\cdot$ E61 J61 J68 $\cdot$ J21 $\cdot$ E66

Pooja Misra

pooja.misra@bimtech.ac.in

Jaya Gupta

jaya.gupta@bimtech.ac.in

1 Birla Institute of Management Technology, Plot No. 5, Knowledge Park - II, Greater Noida 201 306, India 


\section{Introduction}

The coronavirus outbreak, which can also be termed as a black swan event, has disrupted the rapid economic growth of countries globally. Tracing back history, the Spanish flu of 1918 had hard hit the world which resulted in loss of lives of 50-100 million globally with India suffering the highest fatality of 18 million lives. To diminish the havoc that such a pandemic can inflict on the lives of people, the Indian Government imposed a nationwide lockdown effective 25 March 2020. The shortcoming of any lockdown is that economic activity comes to a complete standstill.

Based on lack of economic activity, IMF in the World Economic Outlook (Kaur 2020) projected the growth numbers for India 2020-2021 to be at $1.9 \%$. Due to disruptions in demand and supply chains, World Bank's estimates show that Indian economic growth is likely to be in the range of $1.55 \%$ to $2.8 \%$ in 2020-2021. Growth projections forecasted by the International Monetary Fund (IMF) for the global economy have been revised from $3.3 \%$ to a contraction of $3 \%$. Along with this, health and well-being of millions of people have been at risk. Researches are being conducted in several parts of the world to discover a vaccine and possible treatment of the virus. However, the possibility and viability of this being successfully done is not very clear or visible in near future. The only possible means or option available to survive the pandemic infection and reduce the spread of the infection is to implement social distancing and live in a controlled environment.

The virus has also been instrumental in sparking a huge economic crisis. It has simultaneously adversely impacted the supply, i.e. production of goods \& services, and the demand, i.e. consumption, investment, exports and imports. The economic damage due to this health crisis is likely to affect more people in India than the disease. Q1 2020 has been negatively impacted by the lockdown. Q2 and Q3 are expected to be riddled with consumption levels being at an all-time low, business investments declining and exports gradually pointing downwards resulting in an adverse impact on the Indian economy.

As the COVID-19 cases in India were seen to be rising, the lockdown was announced to flatten the curve of this infection and reduce the spread of this infectious disease by breaking important chains of transmission. "India chose to sacrifice its economy and save lives"- “जान हैं तो जहान है". Therefore, it implied that all economic and social activities which require physical presence were either postponed or brought to a halt in its tracks. The recovery curve as being forecasted by analysts and economists is ranging from a best case scenario of "V"shaped recovery curve to "U", "W" or "L". A "V"- or "U"-shaped curve is associated with the timing and extent of stimulus provided by the Government and how companies and market structures are able to cope with decreasing demand.

With the number of coronavirus cases in India on the rise, the lockdown has been extended four times and is in force till 31 May 2020, as of date. Early lockdown announced by the Government of India helped slowdown the spread of the infection in the country. However, it has raised issues of escalating inequalities 
and susceptibilities of marginalized communities within the country. This lockdown and its subsequent extensions, has resulted in disrupting life of all. The lockdown caused confinement of millions of citizens in their homes. Businesses across the length and breadth of the country were shut, and nearly all economic activity was stopped, thereby negatively impacting workforce employed in both the formal and informal sectors. Construction sites were abandoned after the announcement of lockdown. At the same time, most of the residential societies and colonies shut their gates for all but the residents. The prominent sectors which employ migrant workers who are essentially members of the informal economy, are construction and building industry, manufacturing units, trade setups, transport, and hospitality. Also, some of these migrant workers might work as domestic helpers (maids, drivers or watchmen), street vendors, workers in tiny and roadside businesses (tea-shops, dhabas, etc.) or as help in salons and gyms. As per an estimate of Centre for Monitoring Indian Economy (CMIE), nearly 122 million people in India were jobless in April 2020 itself, of which a large majority are small traders and wage labourers. Thus, this precarious situation has resulted in serious crisis and dislocation for migrant workers.

According to the Economic Survey of 2018-2019, the informal economy is constituted of $93 \%$ workers. Census 2011 suggests that there are 450 million internal migrants in India. The actual numbers currently are likely to be much higher than these figures. Primarily, two types of migrations are common in India: the first being longterm migration which is attributed to the resettlement of an individual or household; the second being essentially short-term or seasonal/circular migration, which implies to and fro movement between a source and destination. Approximately 175 million migrants in India are those who travel for work in the informal sector. They are the lifeline of many State economies.

This pandemic and the subsequent lockdowns have forced several amongst these workers accompanied by their families, to seek shelters in government run relief camps for food and basic needs. Indian Central and State Governments have been setting up of additional relief camps for them to live. The migrant workers have been through enormous mental, financial and emotional agony in urban centres and industrial belts and are migrating back to their native villages in enormous numbers. The agony of these workers has been due to many fold reasons such as lack of jobs and livelihood, absence of social security and being stranded in an alien city and State. The absence of public transportation during the lockdown compelled these stranded migrant workers to try to travel by foot or on bicycle to cover hundreds of kilometres back to their native homes in villages. The imposing of lockdown by the Central Government has precipitated a huge "reverse migration" from the "destination" to "source" in large parts of India (Dandekar and Ghai 2020). As per some estimates, more than 120 to 140 million workers are on their way back to the villages. 


\section{Review of Literature}

India, as a country prior to the onset of this health crisis, was already facing a decline in GDP growth and an increase in unemployment rates. There was a demand slowdown, and the lockdown further worsened the demand and supply decline in the economy. Global recession and trouble in global supply chains are further aggravating the already disrupted domestic supplies and demand. Both the formal and informal sectors would have to bear the brunt of this crisis.

Coronavirus in India has caused unique challenges for the country. The large population of 1.3 billion living in diverse States with differing levels of health infrastructure, social, cultural and economic inequalities are the major reasons for this. The readiness of State Governments to deal with the virus has differed substantially. Having faced the Nipah virus in 2018, Kerala resorted to extensive testing, contact tracing, etc., to minimize the spread. Similarly, Odisha as a State has witnessed several natural disasters, and adequate measures were taken by State government to deal with it. Migration can be regarded as movement of people from one place to another for a certain period of time (Boyle et al. 1998).

The lockdown resulted in manufacturing being brought to a standstill and disruption of the supply chain due to the countries dependence on the supply of intermediate goods from China. Therefore, production was stopped even though workers and capital both were present in the cities. Further, the demand for goods and services in the economy falls, other than that for essential goods. The Domino Effect operates. To worsen the situation this segment of the population, has hardly any access to savings, resulting in worsening their misery. These workers are the ones who are migrating from the cities to the villages in the hope that at least food and essentials would be available in the village.

Based on the researches conducted, it is seen that majority of the investigations related to the impact of the outbreak of pandemic belong to the health sector and economy. It is being increasingly felt that more in-depth analysis is required to understand the magnitude of the challenges that this pandemic along with a declining GDP growth rate in India has inflicted on the condition of the migrant workers, thereby impacting inequality levels in the economy. It is also imperative to analyse if the public policy measures adopted by the Government are adequate to mitigate the challenging conditions being faced by these workers or is there need for additional economic policy announcements by the Government of India.

The current research aims to delve into assimilating available information in Twitter with regard to the plight of Indian migrant workers due to Covid 19 and a lower economic growth and analyse the same with the objective of: (1) identify the responses of people with reference to challenges being faced by the migrant workers in India due to the Covid 19 pandemic and the subsequent lockdown that was imposed along with an anticipated declining economic growth; (2) critically evaluate the policy responses announced by the Government of India to benefit the migrant workers; (3) suggest additional economic policy measures that can be undertaken by the Government for these workers which can thereby lead to reduction in the widening economic inequality gap. The current study will give 
a bird's eye-view of the impact of Covid 19 and declining Indian growth rates on the predicament faced by migrant workers. It will also analyse the economic policy measures adopted by the Government and suggest policy changes to lessen the misery and challenges faced by these workers.

\section{Material and Methods}

Text mining assists in knowledge extraction from an unstructured pool of textual data. This tool has been accepted widely by researchers and analysts as an analytical tool for analysing data. It is machine learning and natural language processing (NLP) which has enabled the process of mining data to identify patterns and topics in the text. Text mining enables researchers to extract high-quality information and evidence with the help of computational tools and techniques from a large quantity of unstructured data. This process of data analysis and theme extraction is also known as Knowledge Discovery and is supported by machine analysis of text. The process of finding knowledge in data is known as Knowledge Discovery in Databases (KDD). It has been defined by (Fayyad et al. 1996) as "the non-trivial process of identifying valid, novel, potentially useful and ultimately understandable patterns in data". KDD has a multidimensional method which constitutes activities from data collection to knowledge interpretation. The present study follows the KKD process of text mining for the meta trend analysis of textual data, i.e. the compendium of tweets related to "Indian Migrant workers" to analyse the impact of Covid 19 and consequently declining economic growth on the conditions of "Migrant Workers" in India.

\subsection{Data Collection}

COVID 19 has proven to be a major social event which has created huge ramifications for our social system (Teti et al. 2020). A qualitative approach has been used to enable researchers to capture deeper meanings from the dataset. This included labelling popular terms and tweet topics, assigning meaning and themes to the topics and interpreting them to identify the latent issues generated (Braun and Clarke 2006). The researchers therefore implemented qualitative analysis, a useful method for analysing this social phenomenon. It is characterized by the systematic process of coding the data to understand the meaning and description of the social reality by identifying the inherent theme (Zhang and Wildemuth 2009).

Twitter data can be used to study attitude, trend tracking and population health. The use of social media data enables researchers to gather reports of behaviours and views that are unsolicited and unprompted by the researcher. At the same time, social media provides the opportunity to spot personal expression and human interaction in real time and on a massive scale (McCormick et al. 2017). Twitter is one of the social networking sites being used extensively since it enables all to share and express concerns and views on topics of relevance. 
Trending hashtags related to the problem of migrant labour, such as \#IndianMigrantWorkers, were used as key search terms to collect Tweets on Twitter. The data were downloaded from Twitter with the help of the Twitter API Authentication Process using OAuth package of R. Tweets published between 23 March 2020 and 21 May 2020. A total of nearly 50,000 Tweets have been downloaded and are the dataset for the present study.

\subsection{Data Cleaning and Pre-processing}

On the downloaded data from Twitter, text mining technique was applied for the purpose of automated information extraction from unstructured text data (Rajman and Besancon 1998). It is a scientific process of deriving trends from unstructured textual data, and helps gain an insight into the themes of the dataset and examine the dynamics of the study (Ramage et al. 2009). The data noisiness was cleaned with the help of the R-Programming (R) and statistical software. In this package $\mathrm{R}$ data cleaning is completed by means of the library package "tm". After removing all noise and cleaning of the data, the pre-processing of the Corpus was completed. Thereafter, it involved transforming the pre-processed text into a structured format for actual computation.

\subsection{Data Transformation}

On obtaining the structured cleaned "Corpus", it was transformed into a "TermDocumentMatrix". The TermDocumentMatrix is a mathematical matrix which helps describe the frequency of terms that occur in a structured dataset. The rows tally to documents in the structured text, while columns correspond to the terms. The goal of the TermDocumentMatrix is to characterize the topic of a document by the frequency of semantically significant terms.

\subsection{Establishing Trustworthiness}

In the present study, two researchers were involved in separately interpreting the clusters of tweets that have been formed using unsupervised machine learning to ensure inter-rater reliability (Gwet 2014). The researchers separately labelled the clusters and that became the theme to which that cluster represented.

\section{Results}

\subsection{Data Mining}

The transformed matrix was subsequently used for analysis of data. Data analysis was done based on three models: the first being Wordcloud, second being topic modelling 
and third being sentiment analysis. "Word cloud" or tag clouds are graphical visual depictions of word frequency and provide larger visibility to those words which are more frequently used in the tweets and text. It has been defined as "the visual representation of words for a certain written content structured as per its frequency" (Jayashankar and Sridaran 2017). The study by Sinclair and Cardew-Hall (2008) states that word cloud is an initial stage for an exhaustive analysis of certain text material. Thus, post-Word cloud visualization, topic modelling of the themes and topics was done for an in-depth investigation of the tweets.

Advancement in natural language processing (NLP) and machine learning has led to the development of a probabilistic framework text mining approach called topic modelling. It enables researchers to establish and encapsulate electronic archives at a scale that would be impossible by human annotation and use algorithms (based on Gibbs sampling) for discovering the main themes that pervade a large and unstructured collection of documents. It uses the primary technique of latent Dirichlet allocation (LDA) and is akin to discrete PCA, i.e. principal component and factor analysis. LDA and other topic models are part of the larger field of probabilistic modelling (Blei 2012). The dataset is analysed into a few topics. The graphical representation helps understand the topics that are extracted from the tweets. The topics may contain words from several topics in different proportions, i.e. in a two topic document it can be interpreted that "Document 1 is $80 \%$ topic A and $20 \%$ topic B, while Document 2 is $35 \%$ topic A and $65 \%$ topic B". The identified topics were deliberated upon by two domain experts from the field to interpret the data. The two experts labelled these topics and identified the theme to which the topic belongs.

\subsubsection{Sentiment Analysis}

Sentiment analysis or opinion mining has been defined as "the computational study of opinions, sentiments and emotions expressed in text" (Liu 2010). It can be regarded as a form of text analysis that helps to extract and analyse opinion oriented text to determine positive and negative views/ opinions about an event/ product/person or topic. A large mass of people express their views on various aspects freely on Twitter. Therefore, these tweets can be regarded as useful source of information to infer people's opinion on pertinent social issues.

As an important method for undertaking social media research, sentiment analysis can be regarded as a computational and natural language processing-based method to scrutinize the prominent sentiments and emotions of people in the given texts (Beigi et al. 2016). In the present study, based on the NRC Emotion Lexicon, the sentiment analysis has been done (Mohammad and Turney 2013). Two sentiments (negative and positive) and eight basic emotions (anger, anticipation, fear, surprise, sadness, joy, disgust and trust) that are associated with English words and languages characterize The NRC Emotion Lexicon. The "syuzhet" package in R was used to capture people's emotions in text. 


\subsection{Data Interpretation and Knowledge Discovery}

\subsubsection{Word Cloud}

The word cloud consists of the most used words from the tweets which mentioned Indian Migrant labour. The prominent or keywords figuring repetitively in the tweets and communicating the sentiments of the people are represented graphically. In the graphic based on the frequency of occurrence in the text, the more prominent words appear larger in size and bold creating a visual emphasis (Conner et al., 2020).

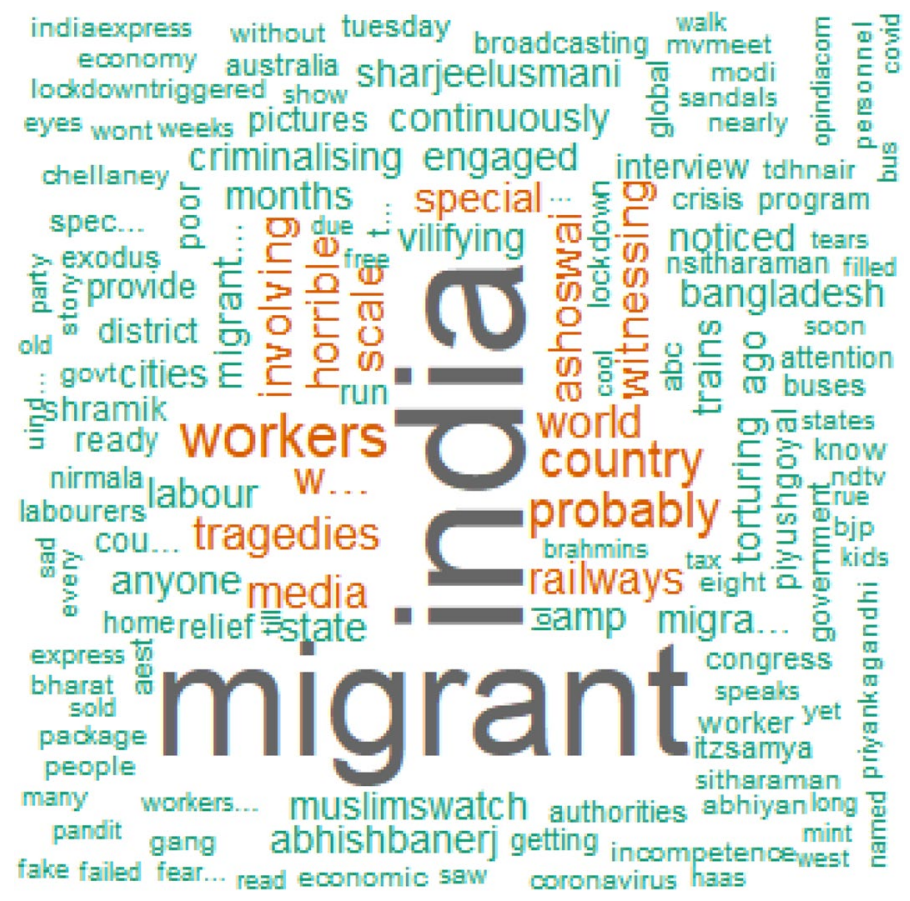

The image highlighted three words prominently, "India", "Migrant" and "Workers" indicating that the migrant workers have been adversely impacted in India. In terms of how these migrant workers were impacted, words like "tragedy", "horrible" "scale", "crisis" and "torturing" emerged as major terms. Additionally, in terms of help extended to the migrant workers, words such as "Shramik", "Railways", "Trains" and "buses" emerged. These terms were further explored in detail by the researchers by examining full sentences in tweets. One tweet suggested, "In India migrants are from Indian villages that work in the cities have been affected by this 
horrible tragedy". Similarly, some others are related to relief measures, "Modi Govt arranged hundreds of special trains for migrant workers!"; "Indian government arranges special trains and buses to help stranded migrant workers."

\subsubsection{Topic Modelling}

Topic modelling analysis of Twitter data was done to identify the key themes representative of public sentiment related to the migrant labourers in India. These represent the main topics or key phrases that emerged from the tweets on the social platform related to reverse migration of workers after the lockdown.

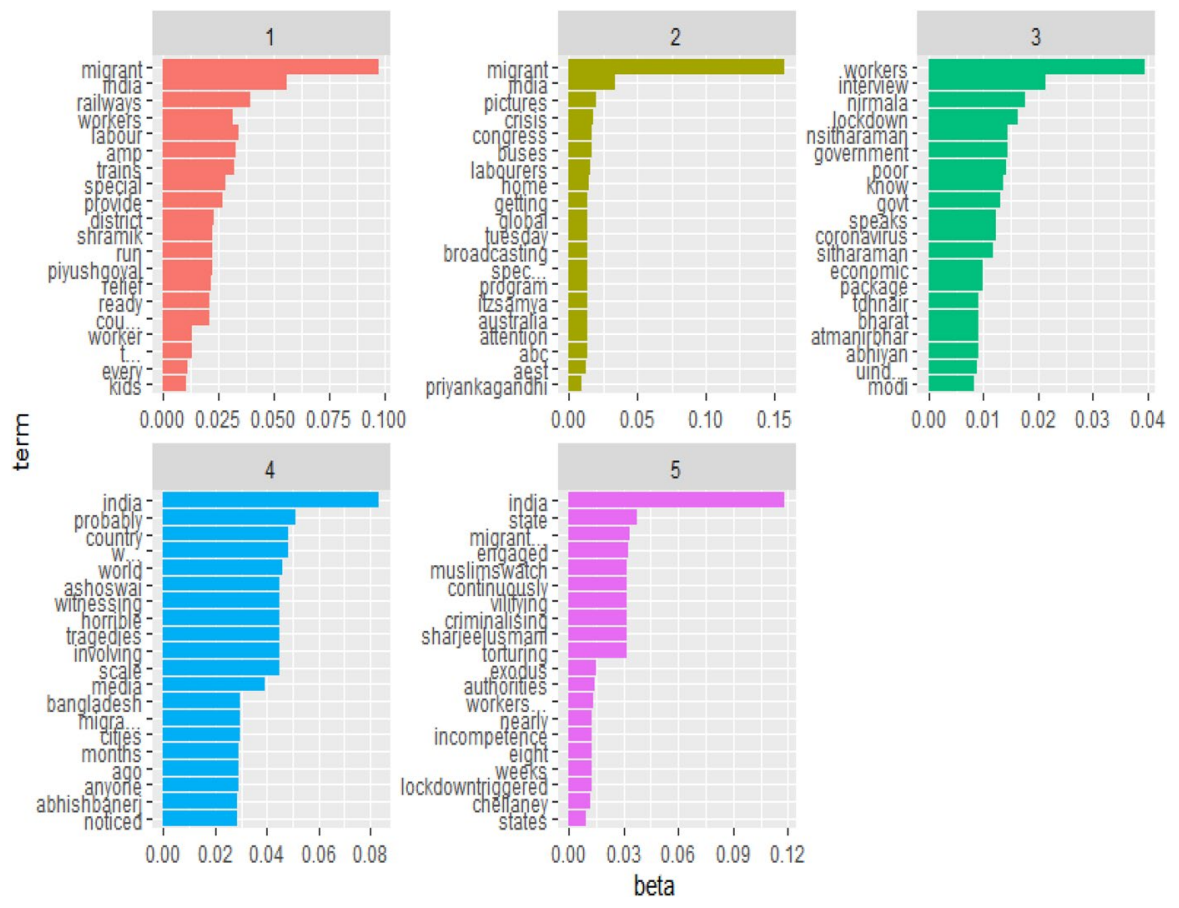

The two researchers subsequently discussed the terms and sample Tweets in the five topics that emerged and categorized them into common themes. To protect the privacy and anonymity of the Twitter users of these sample Tweets, the researchers have used either excerpts of Tweets or paraphrased them in the message. Table 1 in Appendix 1 presents the results of identified five salient topics, most popular words within each topic and some sample tweets related to each topic. 


\subsubsection{Sentiment Analysis}

\section{Sentiment Scores for Indian Migrant Labourers during Covid 19}

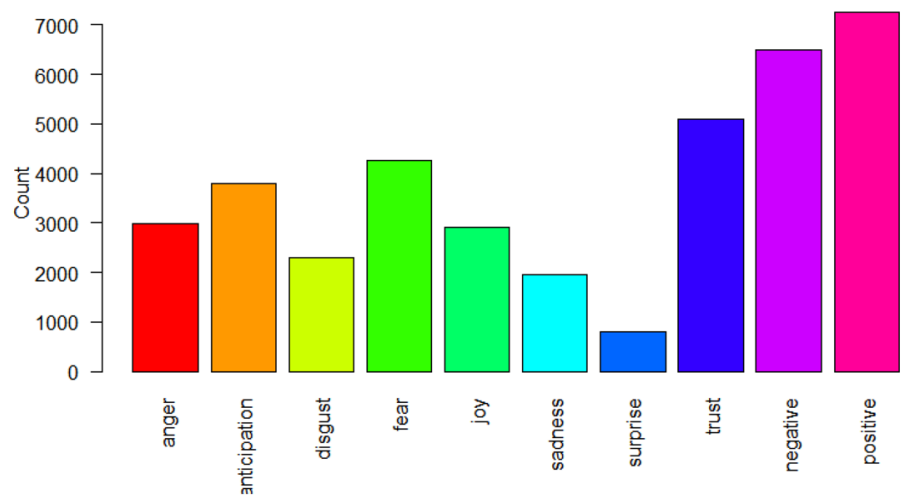

The above plot shows that tweets are more related to trust and fear. This suggests that though there is confidence and trust in the minds of masses about tiding through this crisis with government support, however, a fear element is also present. People do have some negative feelings on Twitter. However, positive sentiments are more prominent than the negative emotions. But overall, people on Twitter are optimistic about the positive outcomes of reverse migration. The possible reason for the optimism in the masses could be that the tweets include ones related to the Rs. 20 trillion economic package (equivalent to $10 \%$ of India's GDP, USD 265,197,400,000) announced by the Finance Minister to provide a boost to the economy.

\section{Discussion and Conclusion}

The results of the analysis highlight five major themes of discussion. On the one hand, the discussion reflects the rescue operations, help being provided and the government relief package to bring about self-reliance and self-sufficiency. On the other hand, the scale of this unforeseen tragedy and the pain due to the lockdown imposed to ensure social distancing with the aim to curb the spread of the pandemic is seen. These could be the primary factors for the shift in Prime Minister's address during the announcement of second lockdown. In the first lockdown, he emphasized the importance of- "जान है तो जहान है" (i.e. saving life is of utmost importance), while in the second the direction that he gave to his countrymen was of "जान भी और जहान भी, दोनो है जरूरी" (i.e. life also and economics/well-being also).

This indicates the desire of the government to focus on revival of economic activities and start the production and economic process in a manner that the fight against the virus is also not affected and the economy moves gradually back to normalcy with caution. 
"...a future where people care about both the aspects, follow their duties and abide by the directions of the government - this will be important for India's prosperous and healthy future," PM Narendra Modi.

As seen in the topics identified, the pandemic, which initially started as a medical emergency, has now evolved into an economic calamity, with severe ramifications for all sections of society. Workers in the informal sectors have been hit very badly because of the lockdown measures implemented by the government in a bid to contain the spread of the pandemic. Majority of them have migrated back to their native villages and have no means of livelihood and no savings. It is very important to protect and help them to tide over the shock. A concentrated joint effort by the State and Central Governments working hand in hand is critical to the country successfully overcoming this crisis and restoring normalcy.

Central Government has announced a major relief package to help the rehabilitation drive of migrant workers, ensuring that they become "आत्मनर्भर्भर, i.e. selfreliant in their native villages. These policy measures include key measures, both short term and long term, to help them ride through the present crisis. The details have been included as Appendix 2.

Post the announcement of policy measures of Rs. 20 trillion announced by the Finance Minister, tweets via the hashtag "\#MigrantWorker and Indian Economy" related to people's reactions on the stimulus provided for migrant workers and Indian economy was further analysed and a word cloud was created.

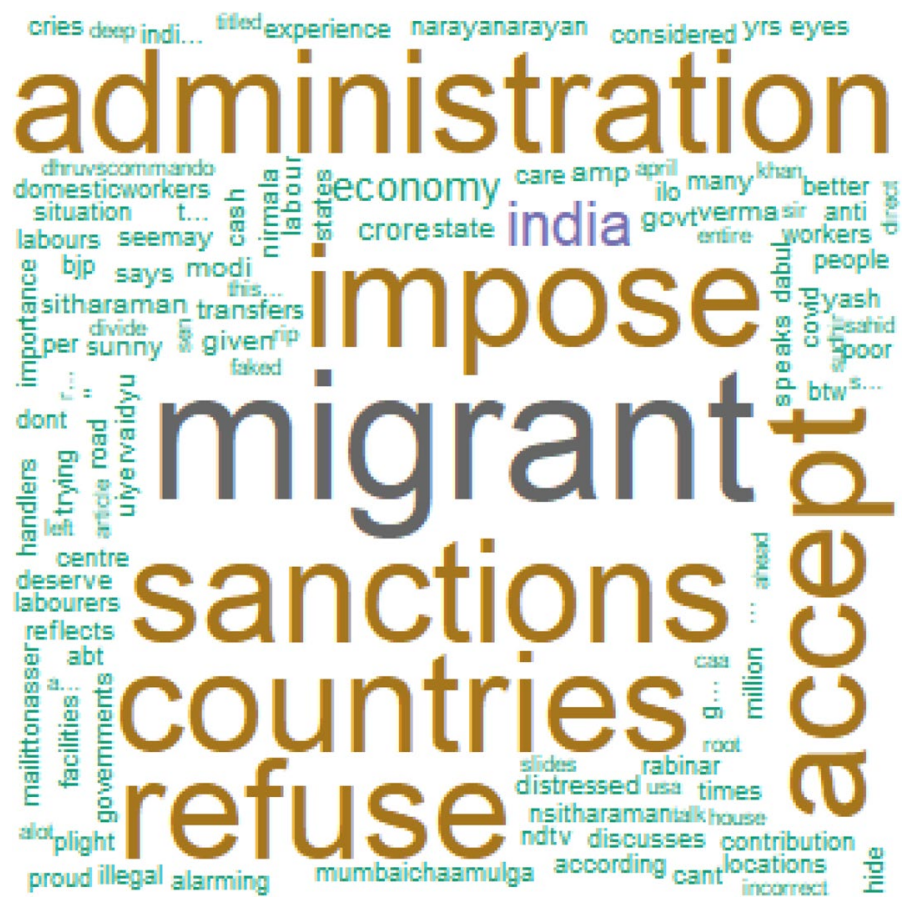


This word cloud highlights some words prominently. "Migrant", "Administration", "Accept", "Sanctions" and "Impose". These highlight the important measures initiated by the administration (i.e. Authorities) to tide over the crisis. Also, other key words like "cash", "transfers", "contribution", "deserve" can be regarded as suggesting the need for providing support to the migrant workers in terms of cash by money transfers to further mitigate their woes. Full sentences related to these terms were extracted. Some of the prominent ones include, "Contribution of migrants labourers to Indian economy is humungous and they deserve better treatment and facilities", "Centre and State Govt should come together to support Migrant Workers and provide cash relief!" "A package is ready for the poor who need immediate help like migrant workers and urban and rural poor. No one will go hungry. The package is worth Rs. 1.7 trillion: Finance Minister Nirmala Sitharaman".

\subsection{Implications of Reverse Migration on Cities}

1. Continuous large-scale reverse migration of labour would result in severe scarcity of semiskilled and unskilled workers in all the urban centres across the country.

2. Businesses which are operating in the organized sector would face major difficulties in resuming operations.

3. Labour-intensive sectors are likely to feel the pain to a greater extent.

4. Less supply of labour could lead to an inevitable rise in wage rates.

\subsection{Implications of Reverse Migration on the Migrant Workers}

1. The desire and the ability of the migrant labour to return to work after the lockdown is lifted remains to be seen. Their decisions could be driven by a number of factors.

a. Extent of pandemic-related fears in metro cities,

b. Ease of mobility in the country after the lockdown is lifted.

c. Having experienced the worst in cities, there is a strong realization amongst them that the cost of living in rural areas is only a third of what it is in the city.

d. Some migrant workers might be owning small tracts of dry land. With small investment, this land could be turned into a productive fertile ground.

The employment opportunities that are available in the rural sector and the extent to which these workers can be successfully absorbed in the agrarian sector would be dependent upon the support extended by the State Government, cropping cycles and their skill-set. 
In case support is provided, they could invest in fertilisers, irrigation infrastructure, transportation and other components required to grow and sell produce in their own land. An effort to help them with financial planning and investing in skill development programmes for these workers, would facilitate the integration of these migrants into the rural economies. Rashtriya Krishi Vikas Yojana, Universities of Agricultural Sciences, National Mission for Sustainable Agriculture, Krishi Vigyan Kendras and the Agriculture Skill Council of India could aid in this.

\subsection{The Way Forward}

In addition to the policy measures adopted by the Central Government, the States should view the demographic shift due to the reverse migration as an opportunity to revamp rural infrastructure. These workers can be productively employed in labour-intensive activities, such as small-scale agro-based industries, livestock, food and fodder processing, water management systems, nurseries and seed banks in the States.

The present scenario is providing an opportunity to decongest cities. In this context, Government can take into account Mahatma Gandhi's advice to first develop the rural economy in order to make it self-sufficient. The migrant labour would then have the option of deciding whether to remain in the villages or move to the cities. However, on the flip side, $70 \%$ of India's population is dependent upon the rural economy but contributes $48 \%$ of Net domestic product, as on 2015-2016, according to the latest labour survey of 2017-2018. This suggests that the productivity of the workforce is lower in rural areas. Further, there is over dependence on agriculture, with low diversification. Therefore, creating more employment in rural areas would be tough.

According to a study by RBI in 2014 , the income elasticity for the agriculture sector is 0.04 during 1999-2009. This implies that to bring about an increase of $1 \%$ in employment, this sector needs to have a growth of $25 \%$, which is quite unrealistic considering the average growth of only 3.34\% in 2017-2018 based on data from Central Statistical Organization. The manufacturing and construction sectors, which constitute about $17 \%$ and $10 \%$, respectively, of the net domestic product, can help absorb the additional labour. The estimated elasticity of manufacturing sector is 0.09 as against that of construction sectors at 1.13 . Therefore, the construction sector can help absorb the migrant labour, and the State Government should provide employment opportunities in these two sectors. Increase in manufacturing activities will also help in increasing economic growth of the country. 
The State Governments of UP and Bihar have a tough task in hand. According to Census 2011, 23\% of interstate migrants are from Uttar Pradesh and 14\% are from Bihar. At the same time, rural unemployment rates of these states are at $6 \%$ and $7 \%$, as per Periodic Labour Force Survey. These two states have the highest rates of rural poverty, as nearly $37 \%$ of India's poor live in these two states. The State Governments have initiated steps to tide over this crisis and to transform this tragedy into an opportunity. Bihar government has started skill profiling exercise for the returning migrants so that this data can be utilized by them to create employment opportunities for the utilization of their skills and development of the State. Similarly, the government of UP has also initiated steps to map details of migrants and their skillsets. The government would then provide training to them, ensure social security, employment and loan facilities for these migrants.

The Central and State Governments are taking measures to respond to this challenge. A step taken by the Government in this direction is the announcement of the Garib Kalyan Rojgar Abhiyan scheme of Rs. 50,000 crore on 20 June 2020, wherein 25 different projects in 116 districts across six states will create job opportunities for these migrant workers. Thus, it is imperative on the part of policy makers at both these levels to scale up the responses as the challenges unfold. This is mandatory to minimize the damage and shock caused by this pandemic on the formal and informal sectors. This could help pave the way for a V- or U-shaped recovery for the Indian economy at large and help restart the journey back on the road to rapid economic growth that India has been treading on for more than over two decades.

\subsection{Limitations}

The researchers have only sampled the trending hashtag of "\#IndianMigrantWorker" and "\#MigrantWorker and Indian Economy" to collect Twitter data. Some new hashtags could have become new trending terms for Twitter users over time. Another, major limitation could be that Twitter users are not the representative of the whole population. The opinions and views included in the present study are indicative of only users' opinions and reactions. Since, the non-English tweets have been removed from analysis, results could bring out a new perspective if we include tweets of Hindi and other Indian languages.

\section{Appendix 1}

See Table 1. 


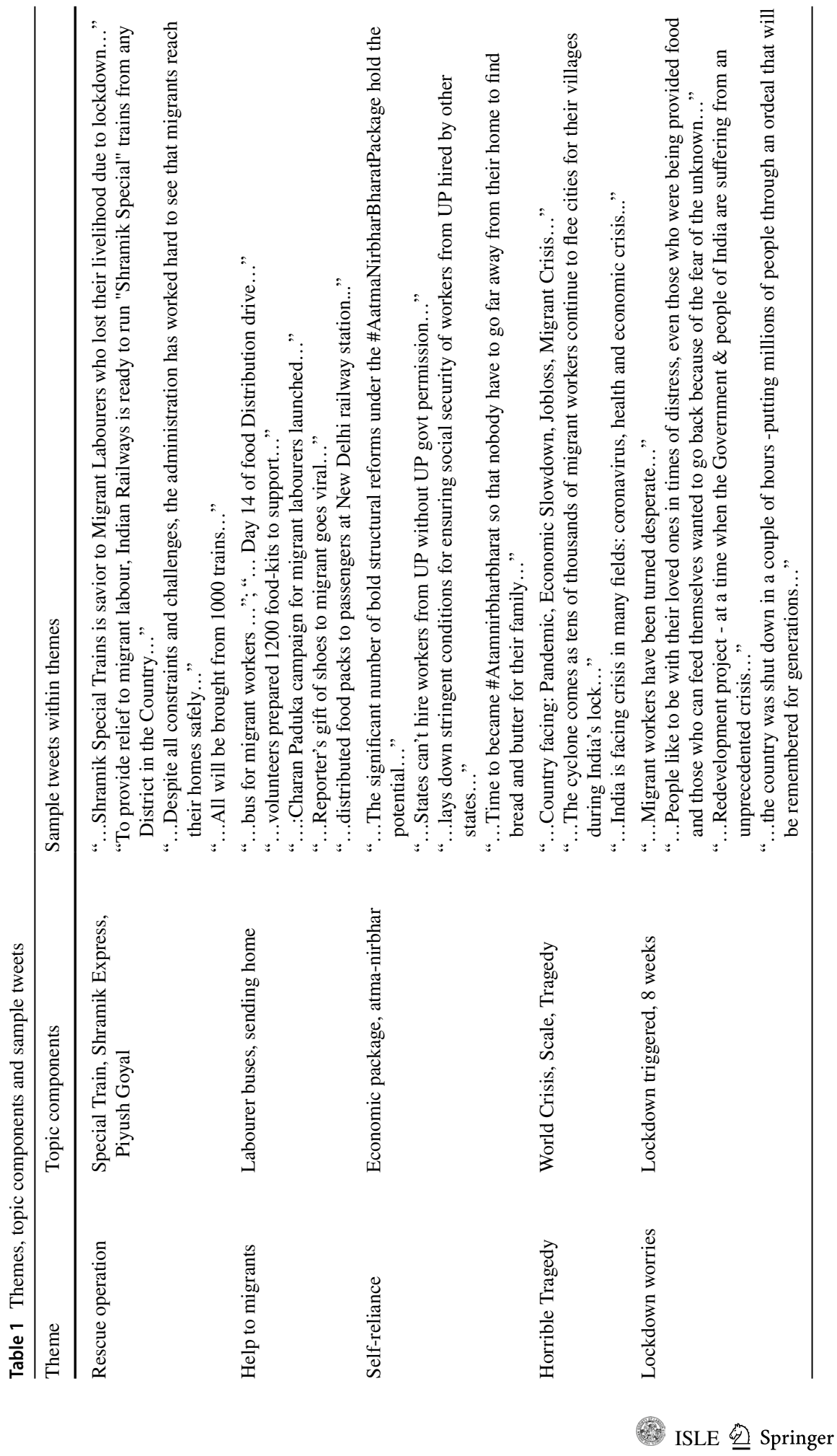




\section{Appendix 2}

Some of the policy measures announced by the Central Government to help them tide over this crisis are:

1. The National Disaster Management Authority (NDMA) has introduced the online dashboard called "National Migrant Information System (NMIS)". The purpose is to monitor the movement of migrant workers and help track the migrant movement to their native places.

2. Comprehensive effort by the GOI to create a database of migrant workers spread across the country. Three primary sources are being considered for this data: relief camps/shelters as per districts, including camps run by non-government bodies and companies; from the employer's premises and also from the clusters in which they reside. This will enable the government to identify migrants who have Aadhar cards, bank accounts and are receiving the benefits of free gas cylinders. Further, this consolidated data would be segregated according to their occupations. The whole exercise would be managed by the district administrations in states with the labour commissioners.

3. The Finance Minister has announced a 65 per cent increase in allocation for MGNREGA in this fiscal. This has been initiated with an aim to help migrant workers find a means to earn their livelihood in their home states. Additional Rs 40,000 crore, has been allocated. Further, the total number of working days have been increased to 300 crore man-days. This has been initiated so that State Governments are able to provide employment to those labourers back home and also employ them during the monsoon season. Work would be provided by States in plantations, horticulture, livestock-related work, etc.

4. The government has promised a free supply of $5 \mathrm{~kg}$ of foodgrain per person and $1 \mathrm{~kg}$ channa per family per month for two months, for those migrants who are neither beneficiaries of the National Food Security Act (2013), or NFSA, nor possess State cards. The government expects eight crore migrants to benefit from this scheme, and the Centre will spend ₹3,500 crore on this. States will be in charge of implementation and distribution.

5. The Central Government is also providing benefits under the "One Nation One Ration Card scheme". Under this scheme, the migrant workers can have access to food in States other than that of their permanent residence.

6. NABARD would provide additional refinance support of Rs. 30,000 crores to rural cooperative and regional banks for crop loan.

7. Special credit facility for street vendors of $5000 \mathrm{cr}$

8. 2.5 crore farmers would be provided Kisan Credit Card (KCC) and can avail of the benefit of concessional loans that are provided through the card. These would include fisherman and animal husbandry farmers.

Funding There was no outside funding or grants received that assisted in this study. 


\section{Declarations}

Conflict of interest The authors declare that there is no conflict of interest.

\section{References}

Beigi, G., X. Hu, R. Maciejewski, and H. Liu. 2016. An overview of sentiment analysis in social media and its applications in disaster relief. In Sentiment analysis and ontology engineering, ed. W. Pedrycz and S.M. Chen, 313-340. Cham: Springer.

Blei, D.M. 2012. Probabilistic topic models. Communications of the ACM 55 (4): 77-84.

Boyle, P., K. Halfacree, and V. Robinson. 1998. Exploring contemporary migration. Essex: Pearson Education Limited.

Braun, V., and V. Clarke. 2006. Using thematic analysis in psychology. Qualitative Research in Psychology 3 (2): 77-101.

CMIE Economic Outlook. "April 2020 Review of Indian Economy: Financial Market Performance”, 5 April, 2020.

Conner, C., J. Samuel, A. Kretinin, Y. Samuel, and L. Nadeau. 2020. A picture for the words! Textual visualization in big data analytics. arXiv preprint arsXiv:2005.07849.

Dandekar, A., and R. Ghai. 2020. Migration and reverse migration in the age of COVID-19. Economic \& Political Weekly 55 (19): 28-31.

Fayyad, U.M., G. Piatetsky-Shapiro, and P. Smyth. 1996. Knowledge discovery and data mining: Towards a unifying framework. KDD 96: 82-88.

Government of India. (2019). Economic Survey 2018-19.

Gwet, K. L. 2014. Handbook of inter-rater reliability: The definitive guide to measuring the extent of agreement among raters. Advanced Analytics, LLC.

http://www.mospi.gov.in/central-statistics-office-cso-1

Jayashankar, S., and R. Sridaran. 2017. Superlative model using word cloud for short answers evaluation in eLearning. Education and Information Technologies 22 (5): 2383-2402.

Kaur, G. (2020). India's Growth Forecast Cut by IMF, Barclays, World Bank, Moody's and Fitch. Retrieved April 24, 2020, from https://www.grainmart.in/news/indias-growth-forecast-cut-by-imfbarclays-world-bank-moodys-and-fitch/.

Liu, B. 2010. Sentiment analysis and subjectivity. Handbook of Natural Language Processing 2 (2010): $627-666$.

McCormick, T.H., H. Lee, N. Cesare, A. Shojaie, and E.S. Spiro. 2017. Using Twitter for demographic and social science research: Tools for data collection and processing. Sociological Methods \& Research 46 (3): 390-421.

Mohammad, S.M., and P.D. Turney. 2013. Crowdsourcing a word-emotion association lexicon. Computational Intelligence 29 (3): 436-465.

Rajman, M., and R. Besancon. 1998. Text mining-knowledge extraction from unstructured textual data. In Proceedings of the 6th Conference of International Federation of Classification Societies.

Ramage, D., E. Rosen, J. Chuang, C. D. Manning, and D. A. McFarland. 2009. Topic modeling for the social sciences. In NIPS 2009 workshop on applications for topic models: Text and beyond (Vol. 5, p. 27).

Sinclair, J., and M. Cardew-Hall. 2008. The folksonomy tag cloud: When is it useful? Journal of Information Science 34 (1): 15-29.

Teti, M., E. Schatz, and L. Liebenberg. 2020. Methods in the time of COVID-19: The vital role of qualitative inquiries. International Journal of Qualitative Methods. https://doi.org/10.1177/1609406920 920962.

Zhang, Y., and B.M. Wildemuth. 2009. Qualitative analysis of content. Applications of Social Research Methods to Questions in Information and Library Science 308: 319.

Publisher's Note Springer Nature remains neutral with regard to jurisdictional claims in published maps and institutional affiliations. 